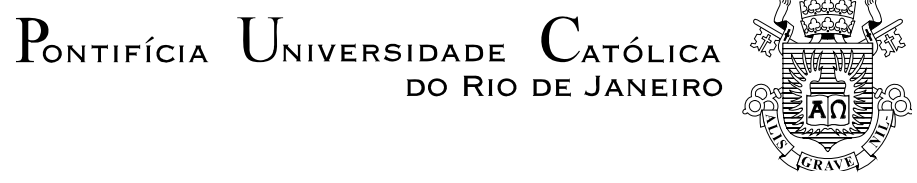

Diana Seixas Bello Moreira

O Poder da Informação sobre as Escolhas de Partidos

Políticos: Evidências a partir de Eleições Municipais.

Dissertação apresentada ao Programa de Pós-Graduação em Economia do Departamento de Economia da PUC-Rio como parte dos requisitos parciais para obtenção do título de Mestre em Economia.

Orientador: Prof. Claudio Abramovay Ferraz do Amaral Co-orientador: Prof. Rodrigo Reis Soares

Rio de Janeiro, março de 2009 
Pontifícia Universidade C $_{\text {atólica }}$

DO RIO DE JANEIRO

Diana Seixas Bello Moreira

\section{O Poder da Informação sobre as Escolhas de Partidos Políticos: Evidências a partir de Eleições Municipais.}

Dissertação apresentada como requisito parcial para obtenção do grau de Mestre pelo Programa de Pós-Graduação em Economia do Departametno de Economia do Centro de Ciências Sociais da PUCRio. Aprovada pela Comissão Examinadora abaixo assinada.

Prof. Claudio Abramovay Ferraz do Amaral Orientador Departamento de Economia - PUC-Rio

Prof. Rodrigo Reis Soares Co-orientador Departamento de Economia - PUC-Rio

Prof. João Manoel Pinho de Mello Departamento de Economia - PUC-Rio

Prof. Octávio Amorim EPGE/FGV

Prof. Nizar Messari

Coordenador(a) Setorial do Centro de Ciências Sociais - PUC-Rio 
Todos os direitos reservados. É proibida a reprodução total ou parcial do trabalho sem autorização da universidade, da autora e do orientador.

\section{Diana Seixas Bello Moreira}

Graduou-se em Ciências Econômicas no IBMEC-RJ em 2006. Cursou o mestrado de Economia da PUC-Rio entre 2007 e 2008.

Ficha Catalográfica

Moreira, Diana Bello Seixas

O Poder da Infomação sobre as Escolhas de Partidos Políticos: Evidências a partir de Eleições Municipais / Diana Seixas Bello Moreira; orientador: Claudio Abramovay Ferraz do Amaral- Rio de Janeiro: PUC-Rio. Departamento de Economia. 2009.

$62 f . ; 30 \mathrm{~cm}$

1. Dissertação (Mestrado) - Pontifícia Universidade Católica do Rio de Janeiro, Departamento de Economia.

Inclui referências bibliográficas.

1. Economia - Teses. 2. Partido Político. 3. Seleção e controle de políticos. 4. Conexão Eleitoral I. Amaral , Claudio Abramovay Ferraz do . II. Soares, Rodrigo Reis. III. Pontifícia Universidade Católica do Rio de Janeiro. Departamento de Economia. IV. Título. 


\section{Agradecimentos}

Aos meus orientadores Claudio Ferraz e Rodrigo Soares por garantirem não apenas que os inúmeros momentos de escuridão terminassem iluminados mas também que os momentos de calmaria fossem passageiros.

Ao Claudio Ferraz e ao Frederico Finan por compartilharem comigo não apenas suas idéias como também sua base de dados sem as quais o estudo seria inviável.

A todas as pessoas que contribuíram com críticas e sugestões encorajando as muitas modificações feitas ao longo do processo: membros da banca, professores participantes do workshop e amigos do microlunch.

Ao Felipe Formenti por tornar todas as minhas aflições e ansiedades em momentos surpreendentemente prazerosos que me deram fôlego quando mais necessitava.

A meu irmão Alan que apesar de distante me orientou com poucas mas sabias palavras.

Aos meus pais e a minha irmã que pacientemente aceitaram a minha ausência continua.

Aos funcionários da biblioteca da PUC e do IMPA que suportaram minha presença continua.

Aos meus amigos de mestrado que foram aqueles com os quais passei mais tempo ao longo desta divertida árdua jornada. 


\section{Resumo}

Moreira, Diana Seixas Bello; Amaral, Claudio Abramovay Ferraz do. O Poder da Informação sobre as Escolhas de Partidos Políticos: Evidências a partir de Eleições Municipais. Rio de Janeiro, 2009. 62p. Dissertação de Mestrado - Departamento de Economia, Pontifícia Universidade Católica do Rio de Janeiro.

Este trabalho apresenta uma análise empírica do papel da conexão eleitoral em influenciar o comportamento de partidos políticos. Exploramos diferenças no acesso que eleitores têm a informação de corrupção para compreender o papel de eleitores na responsabilização de partidos e as conseqüências desta responsabilização sobre o comportamento de partidos políticos quanto à seleção e disciplina imposta a políticos. Usamos o desenho de um programa anticorrupção para gerar a variação exógena na informação disponível a eleitores. O programa selecionou através de sorteios municípios para serem fiscalizados e terem suas irregularidades divulgadas. A periodicidade dos sorteios permitiu-nos comparar municípios com o mesmo nível de corrupção que tiveram o resultado da fiscalização divulgado antes e depois das eleições. Em primeiro lugar, encontramos evidências de que eleitores quando informados do nível de corrupção praticada no município responsabilizam eleitoralmente partidos políticos tanto na eleição para o executivo como para o legislativo municipal. Além disso, mostramos que a informação de corrupção aumenta a probabilidade de políticos permanecerem em partidos menos vantajosos politicamente - partidos pequenos e partidos diferentes do partido do presidente. Estes resultados sugerem que partidos disciplinam políticos. A informação de corrupção também afeta as características do candidato selecionado pelo partido do prefeito. O candidato do partido é mais jovem e menos escolarizado, sugerindo que a informação reduz a capacidade do partido em atrair políticos para se candidatar

\section{Palavras-chave}

Partido político, corrupção, informação, seleção e controle de políticos, conexão eleitoral 


\section{Abstract}

Moreira, Diana Seixas Bello; Amaral, Claudio Abramovay Ferraz do (advisor). The power of Information on Political Party's choices: Empirical Evidence from Municipal

Elections. Rio de Janeiro, 2009. 62p. MSc Dissertation - Departamento de Economia, Pontifícia Universidade Católica do Rio de Janeiro.

In this work we study empirically the role of the electoral accountability in affecting political parties' behavior. We explored differences in voter's access to corruption's information to test if political parties are accountable to voters and the accountability's effect on political parties' choices (politician' discipline and political selection). The design of an anticorruption program generates the exogenous variation on the voter's access to information. The program selects by lotteries municipalities to be audited publicly releasing the audit report. The time frequency of the lotteries allow us to compare municipalities with the same corruption level which have the audit report released before and after the municipalities' election. First, we found evidence that when voters were informed about corruption level they punished political parties in the executive and legislative municipalities' elections. Besides that, the access of information increases the probability that politicians remains in disadvantageous parties - small parties and parties that differs from the president's party. These results suggest that parties discipline politicians. The release of information effects candidate's characteristics. The candidate supported by the mayor's party is younger and less educated, which suggests that the information limit the party's capacity to attract politicians.

\section{Keywords}

Political party, corruption, information, accountability, political selection 


\section{Sumário}

1 Introdução

2 Arcabouço Teórico 13

3 Dados 16

3.1. Programa de Governo Anti-Corrupção e a Construção dos Indicadores de $\begin{array}{ll}\text { Corrupção. } & 16\end{array}$

$\begin{array}{ll}\text { 3.2. Outras Fontes Complementares de Dados } & 17\end{array}$

$\begin{array}{ll}\text { 3.3. Estatísticas Descritivas } & 19\end{array}$

4 Estratégia Empírica $\quad 21$

$\begin{array}{ll}5 \text { Resultados } & 27\end{array}$

5.1. Efeito da informação sobre comportamento de eleitores:

Partidos políticos são responsabilizados por eleitores informados? $\quad 27$

5.2. Papel dos partidos na punição e seleção de políticos. 31

5.2.1. A relação entre partidos e políticos: A informação faz partidos punirem políticos corruptos? 31

5.2.2. Partidos políticos e a capacidade de selecionar candidatos:

A informação muda o candidato do partido? 34

6 Testes de robustez 35

6.1. Transferências de recursos. 36

6.2. Importância do partido político do prefeito em 2004 . 37

$\begin{array}{ll}\text { 6.3. Qualidade do candidato. } & 38\end{array}$

$\begin{array}{ll}7 \text { Conclusão } & 40\end{array}$

8 Bibliografia $\quad 43$

$\begin{array}{ll}9 \text { Tabelas } & 46\end{array}$ 